\title{
RESEARCH ON PM2.5 MASS CONCENTRATION RETRIEVAL METHOD BASED ON HIMAWARI-8 IN BEIJING
}

\author{
Fulin Luo ${ }^{1}$, Juanli Jing ${ }^{1,2,}{ }^{*}$, Anna Wang ${ }^{1}$, Lisi Liang ${ }^{1}$ \\ ${ }^{1}$ College of Geomatics and Geoinformation, Guilin University of Technology \\ ${ }^{2}$ Guangxi Key Laboratory of Spatial Information and Geomatics, Guilin 541004,China
}

KEY WORDS:Himawari-8;AOD;PM2.5;MLR;GWR

\begin{abstract}
:
This paper was based on Japan's new generation of geostationary satellite Himawari-8 2016 Aerosol Optical Depth (AOD) data and near-ground monitoring station PM2.5 mass concentration data, boundary layer height (BLH), relative humidity (RH), normalized vegetation index (NDVI) data to establish a multivariate linear regression model (MLR) and a geographically weighted regression model (GWR) in Beijing.This provided data and scientific basis for the treatment of air pollution. The results show that: (1) The fitting determination coefficient $\mathrm{R}^{2}$ of the MLR was 0.5244 , indicating that there was a significant correlation between PM2.5 and AOD. After GWR model introduced BLH, RH and NDVI in turn, $\mathrm{R}^{2}$ increased from 0.3945 to 0.5403 , indicating that the introduction of relevant influencing factors can improve the accuracy of the model, that was, PM2.5 was affected by BLH, RH and NDVI. (2) The regression coefficients of the MLR and GWR of the BLH, RH and NDVI were statistically analyzed. The regression coefficients of the two models were close to each other, but the standard deviation of the GWR regression coefficients was larger than the MLR, indicating that the local information of the GWR model was more abundant. It reflected the difference characteristics of the regression coefficients of each parameter.
\end{abstract}

\section{INTRODUCTION}

Aerosol is characterized by solid and liquid particles suspended in the atmosphere. Aerosol optical Depth (AOD) is an important parameter of aerosols and is defined as the integral of the extinction coefficient of the medium in the vertical direction.Fine particles with a dynamic diameter of no more than $2.5 \mu \mathrm{m}$ are called PM2.5, which is the main pollutant causing heavy air pollution (Cao,2014).At present, there are two ways to monitor the mass concentration of PM2.5, one is ground-based monitoring and the other is satellite remote sensing. Compared with satellite remote sensing, ground monitoring has higher accuracy, but the spatial coverage of monitoring stations is limited and has certain limitations (Hu et al.,2013).Compared with the traditional ground monitoring methods, satellite remote sensing has the advantage of regional scale, which can reflect the macroscopic distribution trend of

* Corresponding author :Juanli Jing, Email: jjlgut2008@163.com pollutants in large space range and different scales(Hu, et al.2015; Tao et al.,2012). Research scholars at home and abroad have conducted research on satellite remote sensing monitoring of PM2.5 mass concentration:Chen et al.(2014)used the MODIS AOD data and quoted the relative humidity (RH) and boundary layer height $(\mathrm{BLH})$ to construct the relative humidity of the partition. The results show that the zonal relative humidity method has certain research value for studying the correlation between AOD and PM2.5.Zhang et al(2016) established a semi-physical geographic weighted regression model (GWR) to estimate PM10 by vertical correction and humidity correction of AOD and PM2.5. The results showed that the corrected GWR can improve the correlation between PM10 and AOD. The coefficient of determination $\mathrm{R}^{2}$ increased from 0.08 to $0.43 . \mathrm{Li}$ et al.(2018) combined principal component analysis with GWR to construct a geo-weighted model based on principal component analysis (PCA-GWR). The results showed that PCA-GWR was more accurate than GWR .It performed principal component analysis on multiple 
related variables, which can play a role in dimensionality reduction.Wang et al. (2017) used the AOD product of the Himawari-8 satellite and used AERONET AOD as the true value, which confirmed the high precision of the Himawari- 8 AOD data and can effectively characterize the change of aerosol optical thickness. It can be applied to the AOD-PM2.5 correlation analysis of Beijing-Tianjin-Hebei.The mixed effect model was used to estimate the PM2.5 concentration per hour, which proved that Himawari-8 AOD product had certain value in the study of pm2.5 mass concentration.Previous studies have suggested that the correlation between AOD and PM2.5 varies with the spatial environment. Different geographical regions had different aerosol types and GWR was proposed to better limit the spatial heterogeneity of large-scale regression(Fotheringham et al.1996;Li et al.,2016; $\mathrm{Na}$ et al.,2010; Zhang et al.,2015).Traditional research on AOD and PM2.5 basically used MODIS AOD products with a spatial resolution of $10 \mathrm{~km}$ and $3 \mathrm{~km}$, while Himawari-8 AOD has higher temporal resolution and spatial resolution than MODIS AOD.Therefore,this paper estimated the PM2.5 mass concentration in Beijing based on the Japanese meteorological satellite Himawari-8 2016 AOD data, and introduced the boundary layer height (BLH), relative humidity (RH), and normalized vegetation index (NDVI). Multivariate linear regression model and geographic weighted regression model (GWR) were used to analyze the correlation between AOD and PM2.5 and compare the applicability of the two models to air pollution problems in Beijing.

\section{STUDY AREA AND DARASETS}

\subsection{Study Area}

Beijing is located at $115.7^{\circ} \mathrm{E}-117.4^{\circ} \mathrm{E}$ and $39.4^{\circ} \mathrm{N}-41.6^{\circ} \mathrm{N}$. It is located in the north of the north China plain, backed by Yanshan, adjacent to Tianjin and Hebei Province, and has jurisdiction over 16 districts including Dongcheng, Xicheng, Chaoyang, Haidian, Fengtai and Shijingshan. The climate of Beijing is typical north temperate subhumid continental monsoon climate, with high temperatures and rains in summer and cold and dry winters.Beijing has a large and dense population, large demand for resources, and large pollutant emissions. The topography of Beijing's three sides is not conducive to the spread of pollutants, making foggy weather often occur in Beijing, and the problem of air pollution is very serious.

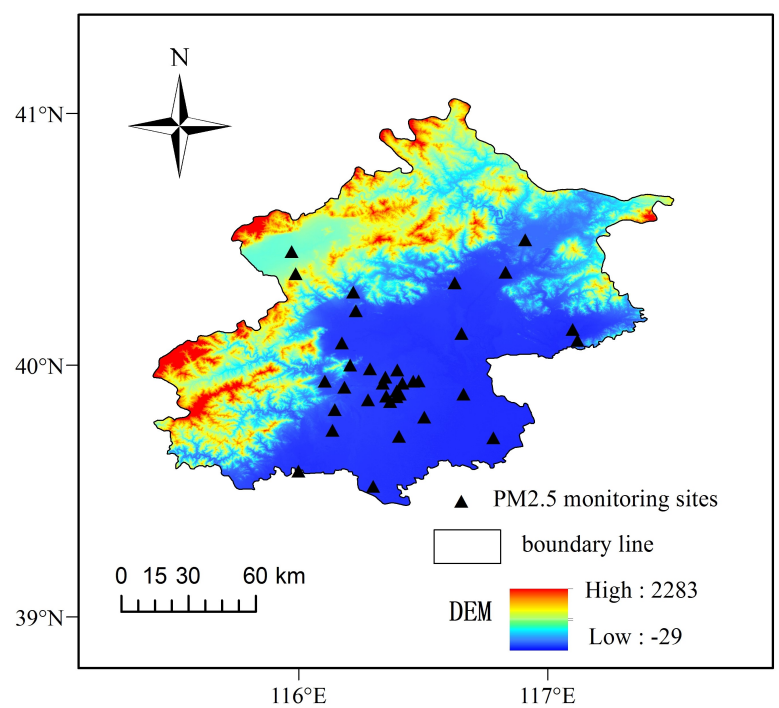

Figure1.Distribution map of Beijing PM2.5 monitoring stations

\subsection{Research Data}

2.2.1 Himawari-8 Meteorological Satellite: The new generation of Japanese geostationary meteorological satellite Himawari- 8 carries the most advanced optical sensor AHI. It has 16 observation bands with a spatial resolution of 0.5 or 1 $\mathrm{km}$ in the visible and $2 \mathrm{~km}$ in near-infrared bands.These advantages, combined with reduced revisit time (approximately 10 minutes in total and approximately 2.5 minutes in the sector), provide new levels of competence for identifying and tracking rapidly changing weather phenomena and for deriving quantitative products (Bessho et al.,2016).Himawari-8 can provide AOD products with spatial resolutions of $5 \mathrm{~km}, 1 \mathrm{~km}$, $2 \mathrm{~km}$ and time resolution: $10 \mathrm{~min}, 1 \mathrm{~h}$.It covers about one-third of the Earth's range (ie West Pacific, East Asia and Southeast Asia, Oceania). This paper used AOD data with a temporal resolution of $1 \mathrm{~h}$ and a spatial resolution of $5 \mathrm{~km}$..

2.2.2 PM2.5 Mass Concentration: The PM2.5 mass concentration data used in this paper was from the PM2.5 hourly average concentration data of ground monitoring from January 2016 to December 2016 in Beijing air quality historical data (http://beijingair.sinaapp.com/).The 35 PM2.5 ground monitoring sites in Beijing are shown in Figure 1.

2.2.3 Meteorological Parameters: Meteorological data, including Relative Humidity (RH) and Boundary layer height 
(BLH). The meteorological data used in this paper was from the reanalysis data set of the European Centre For Medium-Range Weather Forecasts (ECMWF) (ie ERA-Interim). ERA Temporary, one of the ECMWF reanalyzed data sets has provided global climate reanalysis since 1979.

2.2.4 Surface Parameters: This article obtained the MODIS 16-day $1 \mathrm{~km}$ resolution "MOD13A2" and "MYD13A2" normalized difference vegetation index (NDVI) from the MODIS official website (https://ladsweb.modaps.eosdis.nasa.gov/).It was processed to get 8 days of data.NDVI greater than 0.4 usually indicates vegetated areas, while smaller values usually indicate soil-dominated soil surfaces(Liu et al.,2014).

2.2.5 Data Matching: In this paper, the above data was processed and matched by MABLAB programming for modeling, verification and analysis.In space,AOD, meteorological parameters and surface parameters were averaged by non-zero pixels with a radius of $5 \mathrm{~km}$ centered on the PM2.5 site.In terms of time, the data were averaged from 9-16 in Beijing time from January 1, 2016 to December 31, 2016 as the daily average.

\section{RESEARCH METHODS}

\subsection{Multiple Linear Regression Model}

In the real world, the change of the dependent variable is often affected by several important factors. At this time, it is necessary to use two or more influencing factors as the independent variables to explain the change of the dependent variable.This is called multiple regression or multiple regression. When there is a linear relationship between multiple independent variables and dependent variables. The regression analysis carried out is pluralistic regressionn. Let y be the dependent variable, $\mathrm{x}_{1}, \mathrm{x}_{2}, \ldots, \mathrm{x}_{\mathrm{k}}$ are independent variables, and when there is a linear relationship between the independent variable and the dependent variable, then the multiple linear regression model is:

$$
y=\beta_{0}+\beta_{1} x_{1}+\beta_{2} x_{2}+\ldots+\beta_{k} x_{k}
$$

Where $\beta_{0=}$ constant term

$\beta_{1}, \beta_{2} \ldots \beta_{\mathrm{k}}=$ regression coefficients.

\subsection{Geographically Weighted Regression Model}

Geographically weighted regression is a new spatial analysis method proposed in recent years. It is used to detect the non-stationarity of spatial relationships by embedding spatial structures in linear regression models. The geographically weighted regression model used in this study is as follows:

$$
y_{i}=\beta_{0}\left(u_{i}, v_{i}\right)+\sum_{k=1}^{p} \beta_{k}\left(u_{i}, v_{i}\right) x_{i k}+\varepsilon_{i} \quad i=1,2, \ldots, n
$$

Where $\left(\mu_{\mathrm{i}}, v_{\mathrm{i}}\right)=$ coordinates of the ith sample point (such as latitude and longitude)

$\beta_{\mathrm{k}}\left(\mu_{\mathrm{i}}, v_{\mathrm{i}}\right)=$ the $\mathrm{kth}$ regression parameter at the $\mathrm{ith}$ sample point, which is a function of the geographic position.

$\varepsilon_{\mathrm{i}}=$ an independent and identically distributed random error, usually assumed to obey $\mathrm{N}\left(0, \sigma_{2}\right)$.

The spatial weight matrix is the core of the geographically weighted regression model. The spatial position of the data is embedded in the regression parameters, and the point-by-point parameter estimation is performed by the local weighted least squares method. Weight is the distance function between the geospatial position of the regression point and the geospatial position of other observation points. Common spatial weight function methods are: distance threshold method, distance inverse ratio method, Gauss function method, among which the universal application is Gaussian function method. Its function form is as follows(Xuan et al.,2014):

$$
W_{i j}=\exp \left(-\left(d_{i j} / b\right)\right)^{2}
$$

Where $\mathrm{d}_{\mathrm{ij}}=$ the distance between sample points $\mathrm{i}$ and $\mathrm{j}$.

$\mathrm{b}$ is a non-negative attenuation parameter that

describes the functional relationship between weight and distance.

The larger the bandwidth, the slower the weight decays with distance, and the smaller the bandwidth, the faster the weight decays with distance. The AIC information criterion (ie, Akaike information criterion) can be used to measure the goodness of statistical model fitting. The formula of AIC is as follows: 


$$
A I C=2 n \ln (\hat{\sigma})+n \ln (2 \pi)+n\left[\frac{n+\operatorname{tr}(S)}{n-2-\operatorname{tr}(S)}\right]
$$

Where $\operatorname{tr}(\mathrm{S})=$ the trace of the matrix $\mathrm{S}$ of GWR, which is a function of the bandwidth $b$

$\mathrm{n}=$ the size of the sample

$\hat{o}=$ the maximum likelihood estimation of random error term variance, ie for the same sample data, the AIC value is made The bandwidth corresponding to the smallest geographically weighted regression function is the optimal bandwidth.

\section{RESULTS}

\subsection{Variable Statistical Histogram}

Figure 2. mainly illustrated the histogram statistics of the variables used in the model.Overall, in addition to the annual average NDVI and RH showed a bimodal distribution, the overall trend of the remaining variables showed a lognormal distribution.In 2016, the ground PM2.5 concentration ranged from $3 \mu \mathrm{g} / \mathrm{m}^{3}$ to $513 \mu \mathrm{g} / \mathrm{m}^{3}$, and its annual average value was $67.9249 \mu \mathrm{g} / \mathrm{m}^{3}$, exceeding the secondary standard of ambient air quality $\left(35 \mu \mathrm{g} / \mathrm{m}^{3}\right)$. The annual average of AOD was 0.3668 and the standard deviation was 0.2854 . The BLH was mainly distributed between $400 \mathrm{~m}$ and $1500 \mathrm{~m}$, and the maximum and minimum values were $3510.1 \mathrm{~m}$ and $126.1392 \mathrm{~m}$, respectively, and the average value was $1177.5 \mathrm{~m}$. RH was mainly distributed between $22 \%$ and $60 \%$, with a maximum of $102.5811 \%$ and a minimum of $9.6727 \%$. NVDI was mainly distributed between 0.1 and 0.7 , with a maximum of 0.8419 and a minimum of -0.162 .

\subsection{Results of Multiple Linear Regression Model}

Table 1. showed the output of the MLR model, in which PM2.5 was y (dependent variable), and AOD, BLH, RH, and NDVI were $\mathrm{x}_{1}, \mathrm{x}_{2}, \mathrm{x}_{3}$, and $\mathrm{x}_{4}$ (independent variables), respectively. It can be seen from Table 1 . that $\mathrm{R}^{2}=0.5244, \mathrm{~F}=43.65, \mathrm{p}=0.0000$, and $\mathrm{p}<0.05$, the regression model $\mathrm{y}=90.643+142.836 \mathrm{x}_{1}$. $0.028 \mathrm{x}_{2}-0.769 \mathrm{x}_{3}-27.678 \mathrm{x}_{4}$ could be obtained.
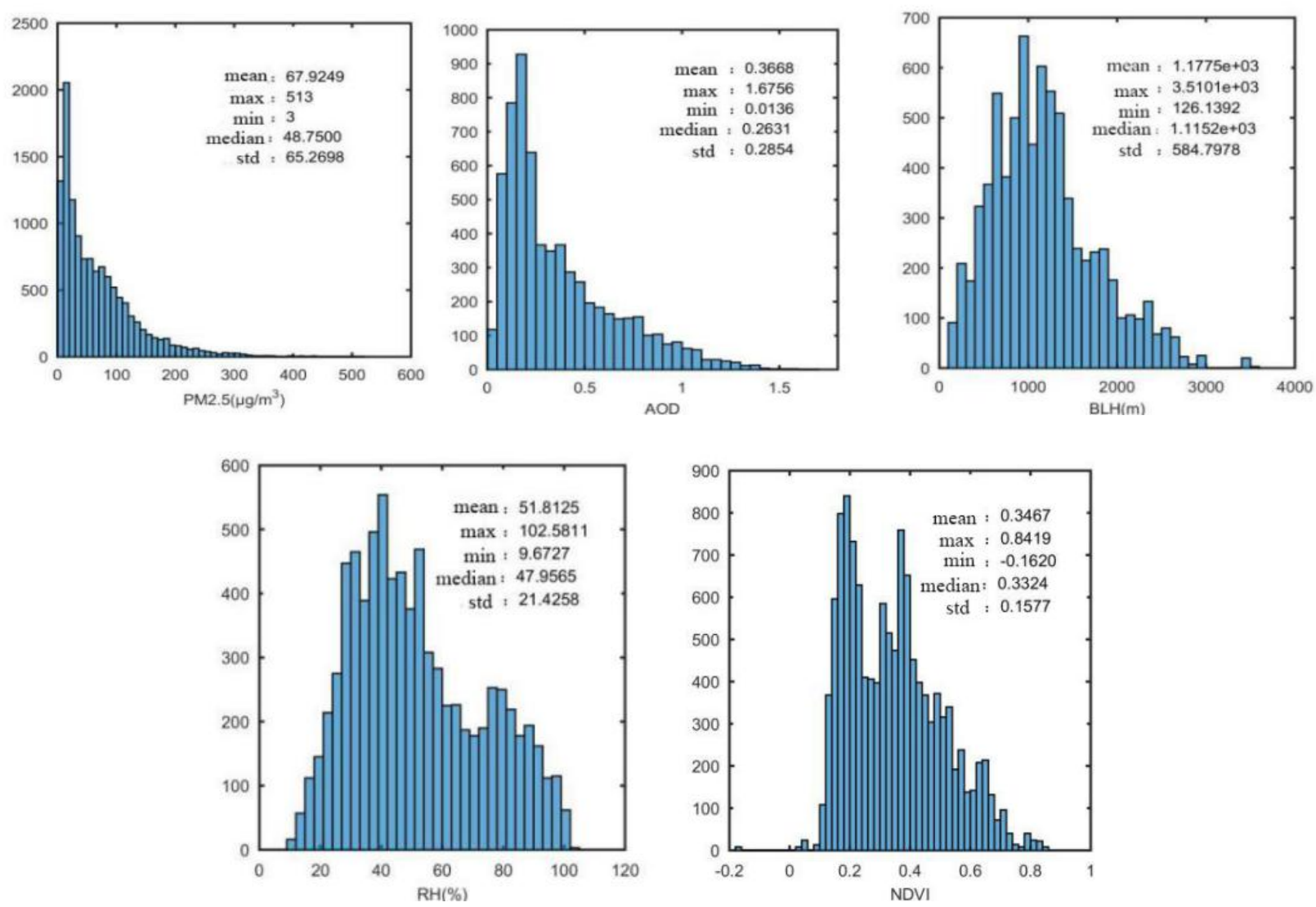

Figure 2. Descriptive statistics of the dataset histogram 


\begin{tabular}{|c|c|c|c|c|c|c|}
\hline \multirow{2}{*}{ model } & \multicolumn{2}{|c|}{ non-standardized coefficient } & \multirow{2}{*}{$\begin{array}{c}\text { standard } \\
\text { coefficient }\end{array}$} & \multirow{2}{*}{ significant } & \multirow{2}{*}{$\mathrm{R}^{2}$} & standard deviation \\
\cline { 2 - 4 } & $\mathrm{B}$ & Standard error & Beta & & & $\mathrm{F}$ \\
\hline 1(constant) & 90.643 & 2.735 & & 0.000 & 0.5244 & 43.65 \\
AOD & 142.836 & 2.777 & 0.670 & 0.000 & & \\
BLH & -0.028 & 0.001 & -0.266 & 0.000 & & \\
RH & -0.796 & 0.051 & -0.204 & 0.000 & & \\
NDVI & -27.678 & 5.965 & -0.065 & 0.000 & & \\
\hline
\end{tabular}

Table 1. Multiple linear regression model output

\subsection{Results of Geographic Weighted Regression Model}

Table 2. was a scatter plot of PM2.5 predicted values and near-surface PM2.5 observations obtained by adding different parameters (including AOD, BLH, RH, NDVI) to the GWR model. After adding the parameters in the GWR model, the coefficient $\mathrm{R}^{2}$ was determined to increase from 0.3945 to
0.5403, indicating that meteorological factors affected the spatial distribution of pollutants. After introducing more suitable parameters, the accuracy of the model was improved, that was, the PM2.5 mass concentration accuracy predicted by the model was improved.

\begin{tabular}{|c|c|c|c|c|c|}
\hline ID & $\mathrm{N}$ & parameter & AIC & $\mathrm{R}^{2}$ & RMSE \\
\hline $\mathrm{a}$ & 6180 & AOD & $65,038.60$ & 0.3945 & 29.3 \\
$\mathrm{~b}$ & 3905 & AOD、RH & $40,898.85$ & 0.4333 & 30.7 \\
$\mathrm{c}$ & 6180 & AOD、NDVI & $64,472.68$ & 0.4496 & 29.38 \\
$\mathrm{~d}$ & 3703 & AOD、BLH & $38,733.87$ & 0.4878 & 31.66 \\
$\mathrm{e}$ & 3905 & AOD、RH、NDVI & $40,692.76$ & 0.4645 & 30.37 \\
$\mathrm{f}$ & 3703 & AOD、BLH、NDVI & $38,627.53$ & 0.5045 & 31.41 \\
$\mathrm{~g}$ & 3405 & AOD、BLH、RH & $35,336.75$ & 0.5356 & 31.7 \\
$\mathrm{~h}$ & 3405 & AOD、BLH、RH、NDVI & $35,314.17$ & 0.5403 & 31.72 \\
\hline
\end{tabular}

Table 2. Comparison of fitting results of different parameters in the model

\subsection{Comparative Analysis of Model Results}

Figure 3. showed the results of the MLR and GWR h models. The slope of the MLR model was $0.52, \mathrm{R}^{2}$ was 0.52 , and RMSE was 37.6. The slope of the GWR model was $0.54, \mathrm{R}^{2}$ was 0.54 , and RMSE was 31.7. Overall, the GWR model fit slightly better than the MLR, but it was not obvious. The reason might be that the scope of the Beijing research area was small, and the monitoring stations within the research scope were relatively close and the number was small, so the effective monitoring data volume was insufficient and the data difference was weak in the data processing process. 

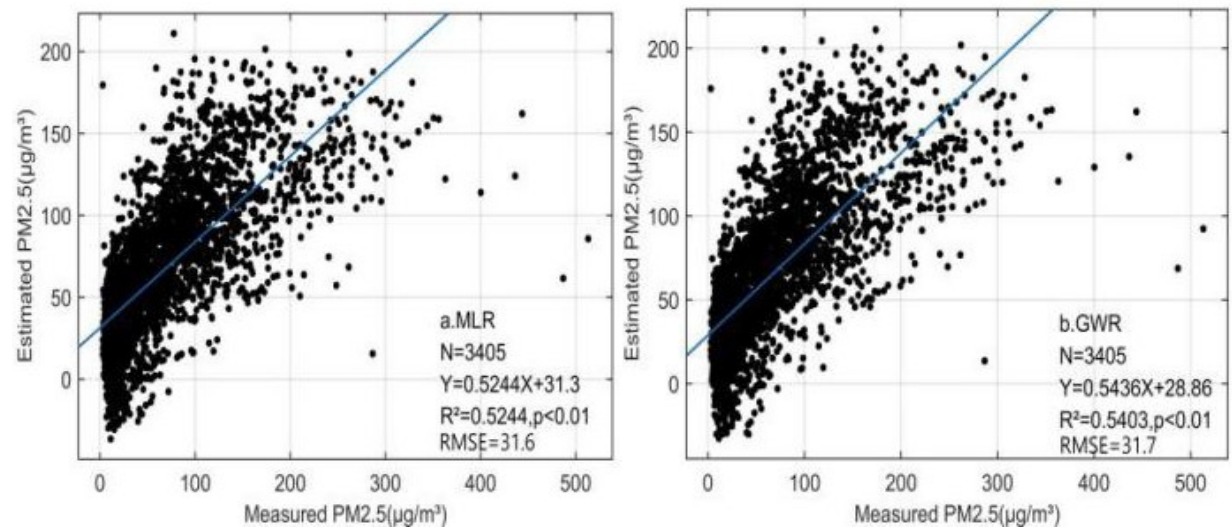

Figure 3. Multiple linear regression (a) and geographically weighted regression (b) fitting results $(\mathrm{N}=3405)$

The average values of the regression coefficients of the statistical MLR model and the GWR model were shown in Table 3. From the table, the regression coefficients of the two models were generally close. The PM2.5 mass concentration was generally proportional to AOD and inversely proportional to $\mathrm{RH}, \mathrm{BLH}$, and NDVI, indicating that the GWR model maintains overall consistency with the MLR model. It was worth noting that from the standard deviation of each regression coefficient, the standard deviation of the regression coefficient of the GWR model was larger than that of the MLR model. This showed that the local information of the GWR model was richer, and it can better reflect the difference characteristics of the regression coefficients of each parameter.

\begin{tabular}{|c|c|c|c|c|}
\hline \multirow{2}{*}{$\begin{array}{c}\text { Regression } \\
\text { parameter }\end{array}$} & $\begin{array}{c}|c| \\
\text { regression } \\
\text { coefficient }\end{array}$ & $\begin{array}{c}\text { standard } \\
\text { deviation }\end{array}$ & $\begin{array}{c}\text { Gegression } \\
\text { coefficient }\end{array}$ & $\begin{array}{c}\text { standard } \\
\text { deviation }\end{array}$ \\
\cline { 2 - 5 } & 142.8360 & 2.7770 & 147.0274 & 5.5040 \\
Beta_AOD & -0.7963 & 0.0512 & -0.8248 & 0.0997 \\
Beta_RH & -0.0280 & 0.0013 & -0.0273 & 0.0026 \\
Beta_BLH & -27.6781 & 5.9645 & -16.3421 & 14.0390 \\
\hline
\end{tabular}

Table 3. Statistics of geographically weighted and multiple linear regression parameters

In order to further analyze the spatial difference of the regression coefficients, the spatial distribution of the regression results in winter was calculated according to the GWR results (see the Figure 4). It could be seen from Figure 4. that the regression parameters all showed obvious regional distribution characteristics. The overall performance of Beta_AOD was the highest in Cheng 8 and Shunyi districts, and the lowest in Fangshan district.Beta_RH indicated the coefficient of moisture absorption, and Miyun, Pinggu, Shunyi and Huairou were relatively largest, and Daxing District was relatively smallest.
The regression parameters of BLH and other regression coefficients were slightly different. The spatial distribution was relatively the largest in the Miyun area, and the Fangshan, Tongzhou and Pinggu areas were relatively the lowest. Beta BLH showed the regional difference of PM2.5 vertical distribution structure to some extent. Beta_NDVI reflected the background influence of plant canopy, and its spatial distribution was relatively high in the city's eight districts and relatively low in other regions. 

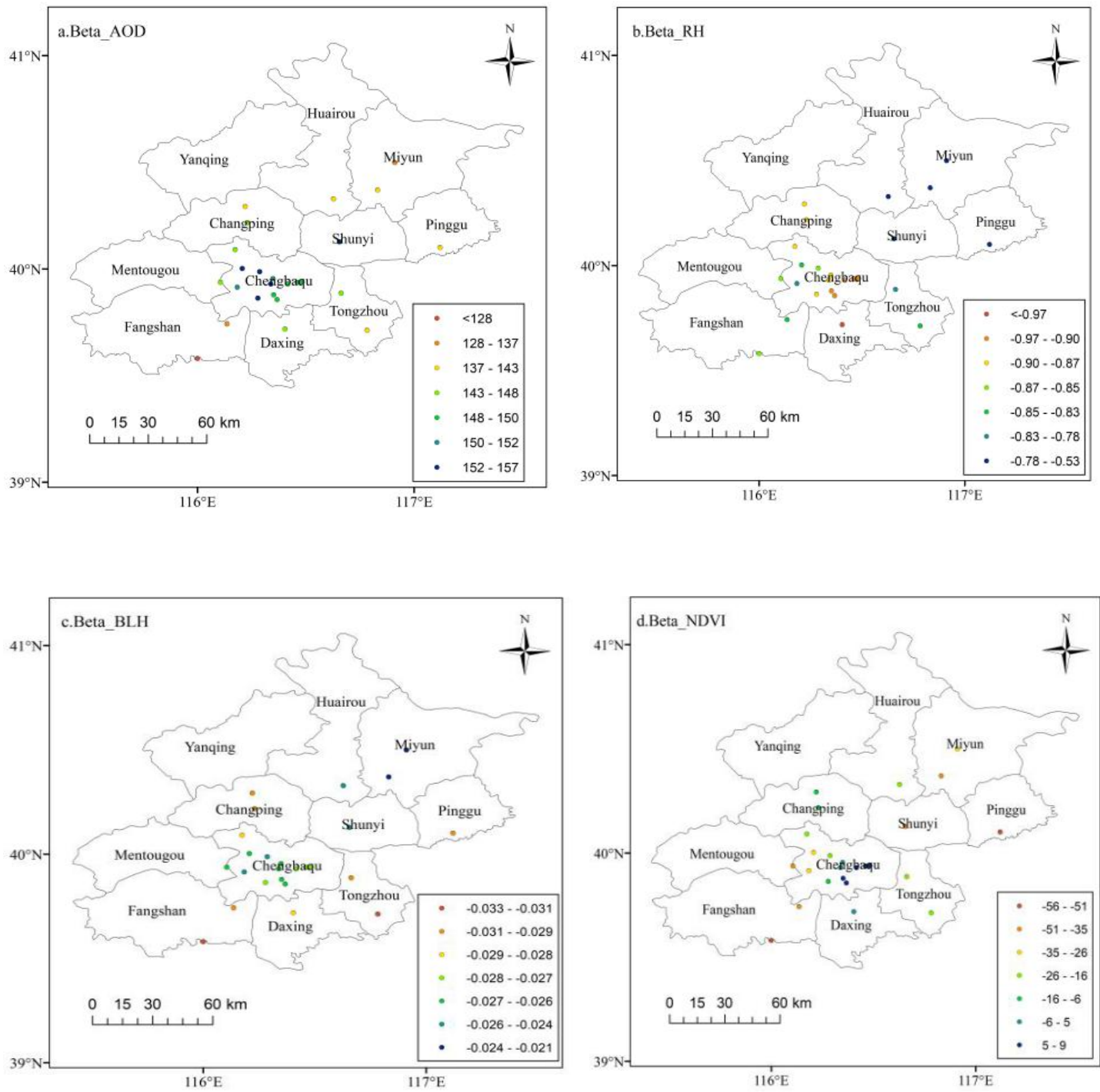

Figure 4. Spatial distribution of the average result of geographically weighted regression parameters

\section{CONCLUSION}

Based on the meteorological data and ground observation data of the Himawari-8 satellite AOD products from November 2016 to December 2016, the correlation analysis between AOD and PM2.5 was carried out by MLR and GWR. The results showed that:

1.The MLR model determination coefficient $R^{2}$ to be 0.4316 and the root mean square error was 47.07 , indicating that there was a significant correlation between PM2.5 and AOD. With the introduction of meteorological parameters into the GWR model, the determination coefficient $\mathrm{R}^{2}$ of the linear correlation analysis between the predicted GWR model values and ground observations increased from 0.3945 to 0.5403 , indicating that the accuracy of the model was affected by meteorological factors and other parameters. From the perspective of goodness of fit, the GWR model was superior to the MLR. And after introducing relevant factors, the accuracy of the model can be improved, and future research will continue to improve the GWR model to map the spatial distribution of PM2.5 concentration with fine spatial resolution.

2.The reason why GWR model did not improve $\mathrm{R}^{2}$ significantly may be that the study area was limited to Beijing, the research scope was small, the number of monitoring stations within the research scope was small and the distribution was close, and the effective monitoring data was insufficient in data processing. The process led to weak data differences, and subsequent research will expand the study area to get more effective data and enhance the data difference. 


\section{ACKNOWLEDGMENTS}

This research was financially supported by Guangxi Key Labor atory of Spatial Information and Geomatics (16-380-25-08), Guangxi young and middle-aged teacher's basic ability improve ment project (KY2016YB192).

\section{REFERENCES}

Bessho,K., Date,K., Hayashi,M., 2016. An introduction to himawari-8/9-japan's new-generation geostationary meteorolo gical satellites.Journal of The Meteorological Society of Japan,94,151-183.

Cao,J.J., 2014.PM2.5 and environment.Science Press.

Chen,H., Li,Q., Wang.Z.T., Mao,H.M., Zhou,C.Y.,Zang,L,J., 2014. Using modis data to monitor the near-surface pm2.5 method in Beijing-Tianjin-Hebei region. Journal of Meteorology and Environment,(5),27-37.

Fotheringham,A.S., Martincharlton., Chrisbrunsdon., 1996.The geography of parameter space: An investigation of spatial non-stationarity. International Journal of Geographical Information Systems, 10(5),605-627.

Gao,Q.X., Li,L., Ma,Z.Y.,Huang,B,B., 2017. The impacts of synoptie situation on heavy pollution process in autumn in Beijing during 2013-2016. Research of Environmental Sciences,30(2),173-183.

Hu,M., Zhang,Y.H., Zhao,Q.B., 2015. Characteristies and sourees of inorganic elements in PM2.5 during wintertime in shanghai. Acta Scientiae Circumstantiae,35(7),1993-1999.

Hu,X., Waller,L.A., Al-Hamdan,M.Z., 2013. Estimating ground-level PM2.5 concentrations in the southeastern U.S. using geographically weighted regression. Environmental Research,121(2),1-10.

Li,G.C., Li,R.R， Lu,Y.M.,Zhao,Y.Y., Yu,B. 2018. Using principal component analysis and geographic weighted regression methods to analyze AOD data. Bulletin of Surveying and Mapping,(4),50-56.

Li,Z., Zhang,Y., Shao,J., 2016. Remote sensing of atmospheric particulate mass of dry PM2.5 near the ground: method validation using ground-based measurements. Remote Sensing Of Environment, 173,59-68.

Liu,H., Remer,L.A., Huang,J. 2014. Preliminary evaluation of s-npp viirs aerosol optical thickness. Journal of Geophysical Research Atmospheres, 119(7),3942-3962.

Na,Z., Yang,Y., Zhou,X., 2010. Application of geographically weighted regression in estimating the effect of climate and site conditions on vegetation distribution in Haihe catchment, China. Plant Ecology,209(2),349-359.

Tao,J.H., Zhang,M.G., Chen,L.F., Wang,Z.F., Su,L., Ge,C., 2012. Method to estimate concentration of surface-level particulate matter from satellite-based aerosol optical thickness. Science China.Earth Sciences. doi.10.1007/s11430-012-4503-3.

Wang,W., Mao,F.Y, Du,L., 2017. Deriving hourly PM2.5 concentrations from himawari-8 AODs over Beijing-Tianjin-He -bei in China. Remote Sensing,9(8),858.

Xuan,H.Y., Luo,S.H., Wang,D.B., 2008. Selecting weighting function and determining bandwidth parameter of GWR model. Journal of Gansu Lianhe,22(3),10-12.

Zhang,T., Gong,W., Zhu,Z., 2016. Semi-physical estimates of national-scale pm10 concentrations in China using satellite-based geographically weighted regression model. Atmosphere,7(7),88

Zhang,Y., Li,Z., 2015. Remote sensing of atmospheric fine particulate matter (PM2.5) mass concentration near the ground from satellite observation. Remote Sensing of Environment, 160, 252-262. 